\title{
Entrevista
}

\section{Natalia Vladimirovna Repkina}

\section{O Sistema Elkonin-Davidov e a formação de professores: contexto russo e ucraniano ${ }^{1}$}

\author{
Fabiana Fiorezi de Marco $^{2}$ \\ Anemari Roesler Luersen Vieira Lopes ${ }^{3}$ \\ Wellington Lima Cedro 4
}

\section{Apresentação}

Para este número temático tivemos a oportunidade de entrevistar a psicóloga, professora e pesquisadora Dra. Natalia Vladimirovna Repkina, cujas pesquisas têm se destacado no campo do ensino desenvolvimental, especialmente sobre Atividade de Estudo e Diagnóstico da Atividade de Estudo.

N. V. Repkina, filha dos psicólogos russos Vladimir Vladimirovich Repkin e Galina Victorovna Repkina, nasceu em 7 de maio de 1954 na cidade russa de Lugansk. Seu trabalho teve grande contribuição no desenvolvimento da teoria e da prática do ensino desenvolvimental (VLADIMIROVNA, 2018).

Ela é graduada em Psicologia e doutora em Ciências Psicológicas. Foi professora do Departamento de Psicologia da Universidade Estatal de Kharkov entre 1972 e 1977. Entre 1997 e 2004 ocupou a chefia do Departamento de Psicologia e Pedagogia do Instituto Siberiano de Ensino Desenvolvimental de

\footnotetext{
1 Entrevista concedida por Natalia V. Repkina à Profa. Fabiana Fiorezi de Marco, durante a realização do IV Colóquio Internacional Ensino Desenvolvimental. Sistema Elkonin-Davidov, realizado na Universidade Federal de Uberlândia, Brasil, no período de 12 a 13 de junho de 2018, com a presença e tradução do ucraniano erradicado no Brasil Andrii Mishchenko. À professora Nathalia V. Repkina, Andrii Mishchenko e aos revisores Anemari Roesler Luersen Vieira Lopes e Wellington Lima Cedro, nossos sinceros agradecimentos.

2 Pós-doutora em Educação pela Universidade de São Paulo (USP). Professora da Universidade Federal de Uberlândia (UFU). E-mail: fabiana.marco@ufu.br.

${ }^{3}$ Pós-doutora em Educação pela Universidade de São Paulo (USP). Professora da Universidade Federal de Santa Maria (UFSM). E-mail: anemari.lopes@gmail.com.

${ }^{4}$ Doutor em Educação pela Universidade de São Paulo (USP). Professor da Universidade Federal de Goiás (UFG). E-mail: wellingtonlimacedro@gmail.com.
} 
Tomsk e, desde 1990, é docente do Departamento de Psicologia da Universidade Nacional de Shevchenko, na cidade de Lugansk, Ucrânia. Repkina é uma das principais representantes do Sistema Elkonin-Davidov na Ucrânia, autora de numerosos livros e artigos científicos sobre ensino desenvolvimental, especialmente sobre Atividade de Estudo e Diagnóstico da Atividade de Estudo.

Para essa entrevista, partimos de alguns questionamentos e dúvidas sobre a formação docente no Sistema Elkonin-Davidov, nos contextos russo e ucraniano. Indagamos à N.V. Repkina sobre aspectos relacionados:

- ao fato do Sistema Elkonin-Davydov (SE-D) ter sido estabelecido como parâmetro oficial da organização e implementação do ensino de escolas russas e ucranianas;

- a relação entre a produção teórica do grupo de pesquisa da universidade e o desenvolvimento dos materiais de ensino;

- o acesso de professores das escolas às ideias do SE-D ou a participação dos professores no processo de elaboração dos materiais pedagógicos do SE-D;

- o que compõem o material didático desse sistema;

- se o SE-D é implementado sempre desde os anos iniciais em uma escola; e

- como ocorre a adaptação de estudantes oriundos de outro sistema.

\section{Entrevista Natalia Vladimirovna Repkina}

Marco: Gostaria de agradecê-la pela disponibilidade de conversar conosco sobre Formação de Professores nos contextos russo e ucraniano. É um prazer recebê-la em Uberlândia para participar do IV Colóquio Internacional Ensino Desenvolvimental: Sistema Elkonin-Davidov. Para iniciar nossa entrevista, a senhora poderia nos contar sobre sua trajetória escolar e acadêmica? Como foi sua aproximação com o Sistema Elkonin-Davydov?

Repkina: Vivi dentro desse sistema. Desde os 5 anos de idade visitava a casa de Davidov. Ele era muito alegre e gostava de crianças. Não fui educada no SE-D, pois estudei anteriormente a ele. No entanto, uma irmã um ano mais nova que eu estudou de acordo com o SE-D, embora a sala de aula onde ela estudava não foi 
filmada ou gravada, pois não existia vídeo, posteriormente a essa época, os pesquisadores do SE-D fizeram uso de filmagens do desenvolvimento do sistema nas escolas para os seus estudos. As crianças que se formaram nesse sistema são pessoas bem criativas e possuem um modo de se expressar impressionante. A maioria entrou em uma universidade sem muitas dificuldades.

Marco: Em algum momento da história da Rússia e da Ucrânia o Sistema Elkonin-Davydov (SE-D) foi estabelecido como parâmetro oficial da organização do ensino das escolas ou ele somente foi entendido como algo experimental em algumas instituições?

Repkina: Sim, foi usado como sistema oficial de ensino nas escolas a partir de 1998. Na Rússia é oficial até hoje. Houve momentos na Rússia que esse sistema foi aprovado, depois reprovado, aprovado de novo e utilizado na Rússia até os dias atuais (06/2018). Na época eram três sistemas: o ensino tradicional, o sistema de Zankov e o Ensino Desenvolvimental. Acredito que o sistema de Zankov parou de ser usado por questões comerciais apenas. Na Ucrânia, o SE-D começou a ser utilizado a partir de 2004 e, recentemente, foi feita uma revisão por parte do ministério de educação da Ucrânia e foi aprovado para ser programa oficial por mais 5 anos.

Marco: Como foi feita a implementação do SE-D nas escolas?

Repkina: Inicialmente o sistema não era obrigatório e os professores de uma mesma escola poderiam aderir ou não. Quando havia um professor que sabia trabalhar no sistema, outros viam, gostavam e começavam a implementá-lo também. Alguns professores aderiram, mesmo não sendo um sistema oficial, de forma discreta e diretores de escolas souberam, começaram a gostar e outros professores também aderiram. Esse processo decorre do fato de que, nesse sistema, o professor apresenta a aula de maneira atraente e outros começam a gostar, implementar em suas aulas e a escola inteira passava a adotar. Houve uma época que um ministro e seu $1^{0}$ secretário foram a favor do sistema e, então, foi garantido por lei uma complementação financeira para professores que o 
utilizassem. Isso começou em 1995, mas não durou muito tempo, cerca de 5 anos. Todos os professores que aderiram ao sistema recebiam uma complementação salarial de 30\%. Nesse processo houve uma desvantagem, pois professores que não foram preparados adequadamente começaram a trabalhar sem realmente compreender o sistema. Naquela época apenas 10\% das crianças estudavam de acordo com o Sistema Elkonin-Davidov. Após o período de 5 anos, iniciou-se uma redução de custos e investimentos na educação sendo que os professores perderam a motivação e deixaram de desenvolver o sistema. Além disso, o professor só poderia trabalhar de acordo como SE-D se a administração da escola estivesse a favor. Hoje ninguém sabe a porcentagem dos que trabalham de acordo com o sistema, mas estima-se algo em torno de 1,5\%. Um motivo dessa redução é o fato de a Rússia ser um país autoritário e não deixar as escolas terem uma autonomia nesse sentido. Em Kharkov começou com uma escola só e foi se espalhando pelo país. Nesse sistema, a criança começa a desenvolver o pensamento e os pais até se assustam, pois elas começam a ensiná-los e quando os professores querem aderir, eles mudam a postura pedagógica, percebem as vantagens do sistema e começam a se modificar.

Marco: Qual era a relação entre a produção teórica do grupo da universidade responsável pela organização do SE-D e o desenvolvimento dos materiais de ensino?

Repkina: Essa relação entre a produção teórica variava em cada grupo de pesquisa. Em Moscou, a teoria era bem diferente da prática, o professor cuidava da parte prática e a parte teórica era dos pesquisadores. As teorias não tinham muita relação com a prática. O objetivo da escola de Moscou era o de compreender como a criança pode entender um conceito teórico. Não se preocupavam em entender se saberiam técnicas como, por exemplo, o modo como iriam somar ou subtrair. Nos tempos livres os professores ensinavam como somar, como subtrair. A prática, a técnica era um trabalho secundário, feito pelos professores posteriormente. Um exemplo dessa separação é quando a criança explica o que é número, mas não consegue identificar onde utilizar em uma 
situação prática. Assim, identificou-se a falha referente à utilização dos conceitos e tentou-se reelaborar isso nos livros didáticos. Em Kharkov, não havia separação entre teoria e prática; professores participavam do processo de elaboração da parte teórica. Essa foi a grande diferença entre Moscou e Kharkov. Nas escolas de Kharkov, as crianças aprendiam os conceitos e a sua aplicação. Mas o objetivo das escolas de Kharkov era entender o que acontece com o pensamento das crianças durante o processo de ensino, pois se não for reconstruído todo o processo de ensino não acontecerá nada com o desenvolvimento mental. (grifos nossos).

Marco: Como os professores da escola tem/tinham acesso as ideias do SE-D? É na universidade? É nos processos formativos em serviço?

Repkina: Essa é uma questão problemática. Não vale a pena iniciar esse processo nas universidades, porque a estatística é de que para cada 60 professores que se formam para o Ensino Médio ${ }^{5}$, apenas dois exercerão a profissão, pois a remuneração não é atrativa. Hoje em dia, na universidade, existem aulas que falam sobre ensino desenvolvimental. Mas, só as aulas têm pouco efeito; é preciso aplicar mesmo, experimentar. Enquanto o aluno, futuro professor, não for para a sala de aula, não irá entender o sistema. Os professores tem uma formação técnica, em primeiro lugar, que os prepara para o ensino dos anos iniciais, com um curso de 4 anos de duração. Nessas escolas técnicas faz sentido estudar o sistema, pois estes futuros professores realmente trabalharão nas escolas. Nos anos iniciais é um professor só para todas as disciplinas e depois do $5^{\circ}$ ano é um professor com formação no ensino superior. É possível um indivíduo ter acesso direto à universidade, mas os professores que passaram pela escola técnica depois para a universidade, são melhores. $\mathrm{O}$ ensino nas escolas técnicas é mais relacionado com a prática do que o das universidades. Nessas, os cursos possuem 4 ou 5 anos de duração e são realizadas discussões mais teóricas, estágios obrigatórios de curta duração que quase não surtem efeito. Nas escolas técnicas a vivência com a prática é contínua. Além disso, ocorreram cursos de formação de professores em que foi ensinado o SE-D. Aqueles que realmente

\footnotetext{
${ }^{5}$ O Ensino Médio a que Repkina refere-se equivale ao Ensino Fundamental II no Brasil.
} 
querem aprender esse sistema passam por esse curso de extensão, que existem ainda hoje em Kharkov. Houve uma experiência de formação de professores na Rússia, no instituto de ensino desenvolvimental. Esses professores faziam papel de crianças e experimentaram o processo. Isso acontecia de maneira muito rápida. Eram 3 semanas seguidas de aula todos os dias, duas vezes ao ano, em período de férias. Eram lecionadas várias disciplinas. Aqueles que passavam por esse processo como crianças, entendiam melhor o sistema. O curso e as respectivas aulas eram planejadas por pessoas formadas no sistema, como pesquisadores e professores que trabalhavam na instituição de ensino desenvolvimental. O curso durava aproximadamente 3 anos e eles estudavam tanto o conteúdo da disciplina quanto a metodologia do ensino. Hoje, os cursos de formação são 3 ou 4 dias apenas, porque as escolas não liberam os professores por muito tempo. Este é um fator que atrapalha a formação do professor, pois em cursos mais longos era possível ele se transformar. Já o curso de curta duração não tem muita eficiência. Quando começou a implementação do SE-D nas escolas, criava-se um núcleo em uma cidade e um grupo de um professor que sabia muito bem o sistema, coordenava o processo de cursos explicando o sistema. V.V. Repkin $^{6}$ e A.A. Zakárova ${ }^{7}$ organizaram um instituto no qual professores que tiveram melhor desempenho em curso de formação no sistema de ensino desenvolvimental se reuniam, apresentavam as aulas aos demais professores como se estes fossem alunos, avaliavam as aulas e o desempenho de cada um. Durante essas reuniões discutiam e identificavam problemas a serem resolvidos. No entanto, para isso, sempre tinha uma pessoa que conhecia muito bem o sistema.

Marco: Como era a participação dos professores no processo de elaboração dos materiais pedagógicos do SE-D?

Repkina: Em Kharkov, Repkin desenvolvia os materiais e os professores levavam para sala de aula. Primeiramente foi criado o próprio programa, depois haviam reuniões com professores e começavam a fazer os projetos das aulas. Os

${ }_{6}^{6}$ Professor de língua russa, psicólogo e pai de N. V. Repkina.

${ }^{7}$ A. A. Zakarova, atualmente, é professora e pesquisadora em Israel. 
professores faziam a implementação da proposta em sua sala e os elaboradores do material observavam a aula e como ela se desenvolvia. Depois disso, discutiam os resultados, como por exemplo, o que deu errado, o que era preciso corrigir e, se necessário, faziam adequações. Era um processo de discussão de 3 ou 4 horas anterior à aula; a própria aula com quarenta e cinco minutos cada uma; e nova discussão após a aula com o professor e o elaborador da proposta. Era um desenvolvimento contínuo da aula, onde sempre ocorria esse processo.

Marco: $\mathrm{O}$ que compõem o material didático?

Repkina: O material didático é uma descrição detalhada do que o professor deve fazer. Zakárova elaborou um material bastante detalhado de cada aula para o professor.

Marco: O SE-D é implementado sempre desde os anos iniciais em uma escola? O que acontece com os estudantes que estudavam inicialmente em outro sistema e depois passam a fazê-lo no SE-D?

Repkina: Tiveram escolas onde o sistema foi implementado desde o $1^{\circ}$ ano e outras a partir do $5^{\circ}$ ano. Para começar com o $5^{\circ}$ as dificuldades são maiores, pois uma desvantagem é o fato de a criança, nesta faixa etária, ter vontade de estudar e, se acontece algo que muda sua percepção neste período, isso vai acompanhá-la pelos anos seguintes. O melhor é começar no $1^{\circ}$ ou $2^{\circ}$ ano, mas alunos que iniciam os estudos no SE-D no $5^{\circ}$ ano, geralmente, não têm dificuldades para se adaptar ao sistema. Para aqueles que apresentam alguma dificuldade, pode-se fazer um trabalho extra com eles. Se chegar um aluno de escola diferente, as crianças o estimulam a não temer pensar e expressar seu pensamento, a não ter medo de errar. É muito importante haver o diálogo entre professor e alunos sempre, pois o professor é ativo no processo e não pode ser eliminado dele. Os alunos não podem ser conduzidos por si mesmos. Durante a aula, eles fazem tarefas em grupos, descobrem leis, regras... sempre em grupos. O professor não deve oferecer respostas prontas para os alunos, mas por meio do diálogo entre professor e alunos, devem apresentar o método que utilizaram para resolver a situação e 
como chegaram ao resultado. Os alunos tem que entender o conteúdo e o sentido do que estão fazendo, esse é o foco do SE-D.

Marco: Agradecemos, mais uma vez, sua disponibilidade. Tivemos a oportunidade de conhecer e de aprofundar questões, além de expandirmos a compreensão sobre a Formação de Professores na Rússia e na Ucrânia, mais especificamente, em ações desenvolvidas para a formação docente e a elaboração de materiais para a sala de aula. Sem dúvida uma contribuição importante para a comunidade de educadores no Brasil que tem buscado aproximar-se de perspectivas transformadoras de sujeitos e de realidades. Muito obrigada!

\section{Referências}

VLADIMIROVNA, Gnevek Olga. Papel da pesquisa de N. V. Repkina no desenvolvimento da teoria e da prática do ensino desenvolvimental. In: PUENTES, Roberto Valdés; LONGAREZI, Andréa Maturano (Orgs). Ensino Desenvolvimental: vida, pensamento e obra dos principais representantes russos (Livro III). Jundiai: Paco Editora/Edufu, 2018. 